\title{
Separation of virgin plastic polymers and post-consumer mixed plastic waste by sinking-flotation technique
}

\author{
Washington Orlando Meneses Quelal ${ }^{1}$ • Borja Velázquez-Martí ${ }^{1}$ (i) $\cdot$ Andrés Ferrer Gisbert ${ }^{1}$
}

Received: 9 March 2021 / Accepted: 20 July 2021 / Published online: 5 August 2021

(C) The Author(s) 2021

\begin{abstract}
The main objective of this research is to separate virgin polymers (PA, PC, PP, HDPE; PS, and ABS) and post-consumer plastic waste from municipal solid waste (MSW) using the sinking-flotation technique. Separation was carried out on a pilot scale in an 800-1 useful volume container with $160 \mathrm{rpm}$ agitation for one hour. Tap water, ethanol solutions, and sodium chloride at different concentrations were used as densification medium. Virgin polymers were separated into two groups: low-density (HDPE and PP) and high-density polymers groups (PS, ABS, PA, and PC). Polymers whose density was less than that of the medium solution floated to the surface, while those whose density was greater than those of the medium solution sank to the bottom. The experimental results showed that complete separation of HDPE from PP achieved $23 \%$ ethanol $\mathrm{v} / \mathrm{v}$, whereas high-density polymers separated up to $40 \% \mathrm{w} / \mathrm{v}$ sodium chloride. Polymer recovery ranged from 70 to $99.70 \%$. In post-consumer recycled plastic waste, fractions of $29.6 \%$ polyolefins, $37.54 \%$ PS, $11 \%$ ABS, $8 \%$ PA, $12 \%$ PC PET, and PVC were obtained. Finally, cast plates were made of the post-consumer waste to properly identify the polymer type present in the separated fractions.
\end{abstract}

Keywords Polyolefins $\cdot$ Recycling $\cdot$ Processing $\cdot$ Density $\cdot$ Concentration $\cdot$ Treatment

\section{Introduction}

Plastics have become a crucial part of our lifestyles as they are highly functional, hygienic, lightweight, and inexpensive (Pol and Thiyagarajan 2010; Pol and Thiyagarajan 2010). Therefore, its world production has increased exponentially during the last 50 years (Singh et al. 2017; Gu and Ozbakkaloglu 2016; Bucknall 2020). Mumbach et al. (2019) estimated that the world's cities generated 1.3 billion tons of solid waste in 2012 and forecast that it will increase to 2.2 billion tons by 2025 . One of the reasons for the increased consumption of plastics is the various applications they have to replace traditional materials (Burat et al. 2009), especially ceramics and wood (Lackner 2015). According to Mancheno et al. (2016), the highest amount of plastics adding up worldwide is made from polycarbonate (PC), polystyrene (PS),

Responsible Editor: Ta Yeong Wu

Borja Velázquez-Martí

borvemar@dmta.upv.es

1 Departamento de Ingeniería Rural and Agroalimentaria, Universitat Politècnica de Valencia, 46022 Camino de Vera s/n, Valencia, Spain polyvinyl chloride (PVC), polyethylene terephthalate (PET), polymethylmethacrylate (PMMA), and acrylonitrile butadiene styrene (ABS) (Rahimi and García 2017). All this has made the presence of plastics indispensable in the modern lifestyle due to versatility and low production costs (AlSalem 2019; Geyer et al. 2017).

However, the problem is that all the plastics generated end up as waste causing negative effects on the environment (Huysman et al. 2017). In addition, the management of plastic waste has not been very successful in recent years, which makes it a challenging project (Sharma et al. 2020; Ferronato and Torretta 2019; Gupta et al. 2015; Vitorino de Souza Melaré et al. 2017; Sharma et al. 2020; Chand Malav et al. 2020; Law et al. 2020). Currently about $80 \%$ of plastic waste is sent to landfills (Ayeleru et al. 2020). However, most plastics take hundreds of years to disintegrate when they are dumped in a landfill. Thus, the increasing amount of plastic waste is exerting great pressure on the limited space of landfills (Takoungsakdakun and Pongstabodee 2007) causing improper management negatively affecting the environment (Aljerf 2016). Furthermore, landfill leachate penetrates into surface waters posing a serious threat to the health of nearby residents (Du et al. 2020). In correspondence with the continuous growth of post-consumer plastic waste and the 
inadequate management of these, there is a special interest in continuing to search for efficient, economic, and environmental alternatives to better manage plastic waste (Bing et al. 2016)

Currently there are various technologies to manage plastic waste. Thus, for example, incineration (Achilias et al. 2007; Guney et al. 2013; Huang et al. 2013) is a widely used alternative to eliminate bulky plastic waste; however, this technique generates a large amount of polluting gases such as $\mathrm{CO}, \mathrm{SO}_{2}, \mathrm{NO}_{2}, \mathrm{HCl}$, and dioxins (Du et al. 2020; Tue et al. 2016). Second, recycling plastic waste is a promising alternative method that generates less pollution and could be very effective (Chen et al. 2011). Recycling involves separating and identifying plastic waste into individual categories for which there are various techniques and methods (Ruj et al. 2015). A very economical separation technology is gravity separation, and it does not generate pollution to the environment. Gravity separation methods include sink-float tanks, jig, shaking table, cylindrical cyclone media separator, and liquid fluidized bed techniques (Pita and Castilho 2017). In this study, for the simplicity of application, the separation by sinking floating is developed; its use consists in varying the density of the aqueous media used in the dense process. Many authors have used this technique to separate polymers, such as polyolefins (HDPE, LDPE, and PP) (Hu et al. 2013). In addition, the sinking-floating separation technique has been and continues to be widely used as a means of separating plastics, especially those that do not have similar density (Dodbiba et al. 2002; Shimoiizaka et al. 1976; Pongstabodee et al. 2008). Some of the means that have been used to recover plastics have been water, solutions saturated with water with sodium chloride, calcium chloride, and ethanol solutions (Fu et al. 2017).

With the aim of improving the procedure and further enriching the literature on the applicability of the technique, the objective of this research is to present as assignment on the separation of different virgin polymers and plastic waste from post-consumer urban solid waste by means of the sinkingfloatation method. In addition, for the separation of polymers and plastics, three aqueous separation methods are used: tap water, sodium chloride, and ethanol. Finally, characteristics of separated fractions of post-consumer waste are evaluated by creating melted plates at several melting temperatures.

\section{Materials and methods}

\section{Materials}

\section{Virgin plastics}

Polymer samples from the Technological Institute of Plastic, AIMPLAS (Valencia-Spain), were used to separate the virgin plastics. Six different types of virgin polymers were used: high density polyethylene (HDPE), polypropylene (PP), acrylonitrile butadiene styrene (ABS), polyamide (PA), polystyrene (PS), and polycarbonate (PC). The virgin PP and HDPE granules had particle sizes between 3.36 and $2 \mathrm{~mm}$ in diameter. Although both polyolefins were white, they presented different tonalities in their coloration; thus, PP was much more transparent than HDPE. The shape of ABS polymer was spherical and yellowish. Likewise, PS displayed a spherical shape, while it had a white-transparent hue. Finally, PC featured a white cylindrical shape, while PA granules presented a rectangular shape and white coloration. Table 1 shows characteristics of the virgin polymers used. Recycled polymer plates are shown in Table 2.

MFI melt flow index

\section{Post-consumer recycled plastics}

As post-consumer recycled materials, plastic waste from solid urban waste (MSW) displayed a certain degree of contamination and deterioration due to labels, inks, impurities, and combinations. The waste analyzed consisted of household packaging such as sheets, bottles, cans, jars, margarine containers, yogurt containers, flowerpots, garden tables, and the like. Samples used were mixed residues of various colors with a non-uniform size and shape.

\section{Experimental procedure}

\section{Virgin plastic separation}

$2.0 \mathrm{~kg}$ samples of each virgin polymers were thoroughly mixed in a pilot scale batch in a tank, Ecomini ML-100 with a useful volume of 800 l. The waste was mixed with tap water agitating at $160 \mathrm{rpm}$ for $1 \mathrm{~h}$ so that the mixtures were completely moistened avoiding air bubble formation. Polymers with a density lower than tap water (PP and HDPE) floated and emerged in the tank while plastic waste with a density higher than tap water (PA, PET, PS and ABS) sank completely. The polymers that sank and floated were centrifuged at $2950 \mathrm{rpm}$ with an MC-250 centrifuge, to remove moisture from the polymers, impurities such as dust and dirt. Then, polymers were weighed to evaluate their recovery as a function of mass balance.

To further separate the polymer mixtures (PP and HDPE) and (PA, PET, PS and ABS) into individual polymers, tap water was replaced by an ethanol and sodium chloride solution. The sodium chloride solution was used with various densities $\left(1.055,1.100\right.$, and $\left.1.175 \mathrm{~g} / \mathrm{cm}^{3}\right)$, while ethanol was single concentration solution $\left(0.935 \mathrm{~g} / \mathrm{cm}^{3}\right)$. Figure 1 shows the initial polymer separation process, where a denser polymer than the medium-density sinks to the bottom. Similarly, the polymer with a lower density than the medium-density floats 
Table 1 Standard main characteristics of virgin polymers

\begin{tabular}{|c|c|c|c|c|c|}
\hline Polymer & Code & Characteristic & Standard & Units & Value \\
\hline \multirow[t]{3}{*}{ PP } & \multirow[t]{3}{*}{ BJ750 } & Density & D1505 ATMS & $\mathrm{g} / \mathrm{cm}^{3}$ & 0.910 \\
\hline & & MFI $\left(190^{\circ} \mathrm{C} / 21 ., 6 \mathrm{~kg}\right)$ & D1238 ATMS & $\mathrm{g} / 10 \mathrm{~min}$ & 28 \\
\hline & & Flexural modulus & D790 ATMS & $\mathrm{Kg} / \mathrm{cm}^{2}$ & 15.500 \\
\hline \multirow[t]{3}{*}{ HDPE } & \multirow[t]{3}{*}{ Lotrène Q TR-571 } & Density & D792 ATMS & $\mathrm{g} / \mathrm{cm}^{3}$ & 0.953 \\
\hline & & MFI $\left(190^{\circ} \mathrm{C} / 21.6 \mathrm{~kg}\right)$ & D1238 ATMS & $\mathrm{g} / 10 \mathrm{~min}$ & 0.020 \\
\hline & & Flexural modulus & D790 ATMS & MPa & 1300 \\
\hline \multirow[t]{3}{*}{ PS } & \multirow[t]{3}{*}{$124 \mathrm{~N} / \mathrm{L}$} & Density & ISO 1183 & $\mathrm{~g} / \mathrm{cm}^{3}$ & 1040 \\
\hline & & MFI $\left(190^{\circ} \mathrm{C} / 21.6 \mathrm{~kg}\right)$ & - & $\mathrm{g} / 10 \mathrm{~min}$ & - \\
\hline & & Flexural modulus & ISO 178 & MPa & 3400 \\
\hline \multirow[t]{3}{*}{ ABS } & \multirow[t]{3}{*}{ ELIX ULTRA HH 4115 PG } & Density & ISO $1183-1$ & $\mathrm{~g} / \mathrm{cm}^{3}$ & 1.070 \\
\hline & & MFI $\left(230^{\circ} \mathrm{C} / 3.8 \mathrm{~kg}\right)$ & ASTM D1238 & $\mathrm{g} / 10 \mathrm{~min}$ & 3 \\
\hline & & Flexural modulus & ASTM D 790 & $\mathrm{MPa}$ & 2000 \\
\hline \multirow[t]{3}{*}{ PA } & \multirow[t]{3}{*}{ PA 6 EXTRUDADA } & Density & ISO $1183-1$ & $\mathrm{~g} / \mathrm{cm}^{3}$ & 1.140 \\
\hline & & MFI $\left(190^{\circ} \mathrm{C} / 21.6 \mathrm{~kg}\right)$ & - & $\mathrm{g} / 10 \mathrm{~min}$ & - \\
\hline & & Flexural modulus & ISO 178 & $\mathrm{MPa}$ & 2800 \\
\hline \multirow[t]{3}{*}{$\mathrm{PC}$} & \multirow[t]{3}{*}{ TECANAT PC } & Density & ASTM 53479 & $\mathrm{~g} / \mathrm{cm}^{3}$ & 1.200 \\
\hline & & MFI $\left(190^{\circ} \mathrm{C} / 21.6 \mathrm{~kg}\right)$ & - & $\mathrm{g} / 10 \mathrm{~min}$ & - \\
\hline & & Flexural modulus & ASTM 53457 & $\mathrm{MPa}$ & 2200 \\
\hline
\end{tabular}

on the surface. Finally, the agitation and centrifugation process in the separation of the polymers with ethanol and sodium chloride were carried out under the same conditions as in the separation with tap water.

\section{Separation of post-consumer recyclable plastics}

Figure 2 shows the process of separating automotive plastic waste with the different solutions (tap water, ethanol, and sodium chloride). Before starting the separation process, plastics were crushed with a RC400 large cutting mill reducing samples size to diameters less than $50 \mathrm{~mm}$. However, to homogenize the samples, size was reduced to $3 \mathrm{~mm}$ diameters using a second $\mathrm{C} 17.26 \mathrm{~s}$ mill (Fig. 3). In addition, the plastics were of different colors, which facilitated the analysis of their separation. Once all the samples had been crushed (12 $\mathrm{kg}$ in total), they were subjected to the separation process with the same conditions (concentration of solutions, tank volume, agitation, and centrifugation) as those used in the separation of virgin polymers. Finally, the compositions and densities of the different mixtures were estimated. The typical densities in the mixtures were determined as an average value of five repetitions.

\section{Recycled polymer plates}

To identify the type of plastic from each separated fraction, plates and sheets were made from each of the fractions. Plates were made by compression using an industrial hydraulic press (FONTUNE PRESES model). The press consisted of two plates, upper and lower, driven by a hydraulic system exerting high pressure. Previously, each fraction particles were distributed in a $20 \times 20 \mathrm{~cm}$ and $0.2-\mathrm{mm}$ thick mold (Fig. 4). Every plastic

Table 2 Recycled polymer plates

\begin{tabular}{lllllll}
\hline $\begin{array}{l}\text { Separation } \\
\text { solution }\end{array}$ & $\begin{array}{l}\text { Concentration } \\
\mathbf{g} / \mathbf{c m}^{\mathbf{3}}\end{array}$ & $\begin{array}{l}\text { Fraction } \\
\text { used }\end{array}$ & $\begin{array}{l}\text { Plate } \\
\text { obtained }\end{array}$ & $\begin{array}{l}\mathbf{T}_{\mathbf{e}} \\
{ }^{\circ} \mathbf{C}\end{array}$ & $\begin{array}{l}\text { Estimated } \\
\text { polymer }\end{array}$ & $\begin{array}{l}\mathbf{T}_{\mathbf{f}} \\
{ }^{\circ} \mathbf{C}\end{array}$ \\
\hline Ethanol & 0,935 & Mix 3 & 1 & $134-201$ & PP & 168 \\
& & Mix 4 & 2 & $110-165$ & HDPE & 137 \\
Sodium & 1055 & Mix 5 & 3 & $176-264$ & PS & 220 \\
chloride & 1100 & Mix 7 & 4 & $180-270$ & ABS & 225 \\
& 1175 & Mix 9 & 5 & $200-300$ & PA & 250 \\
& & Mix 10 & 6 & $140-265$ & PC, PET, PVC & $145-260$ \\
\hline
\end{tabular}




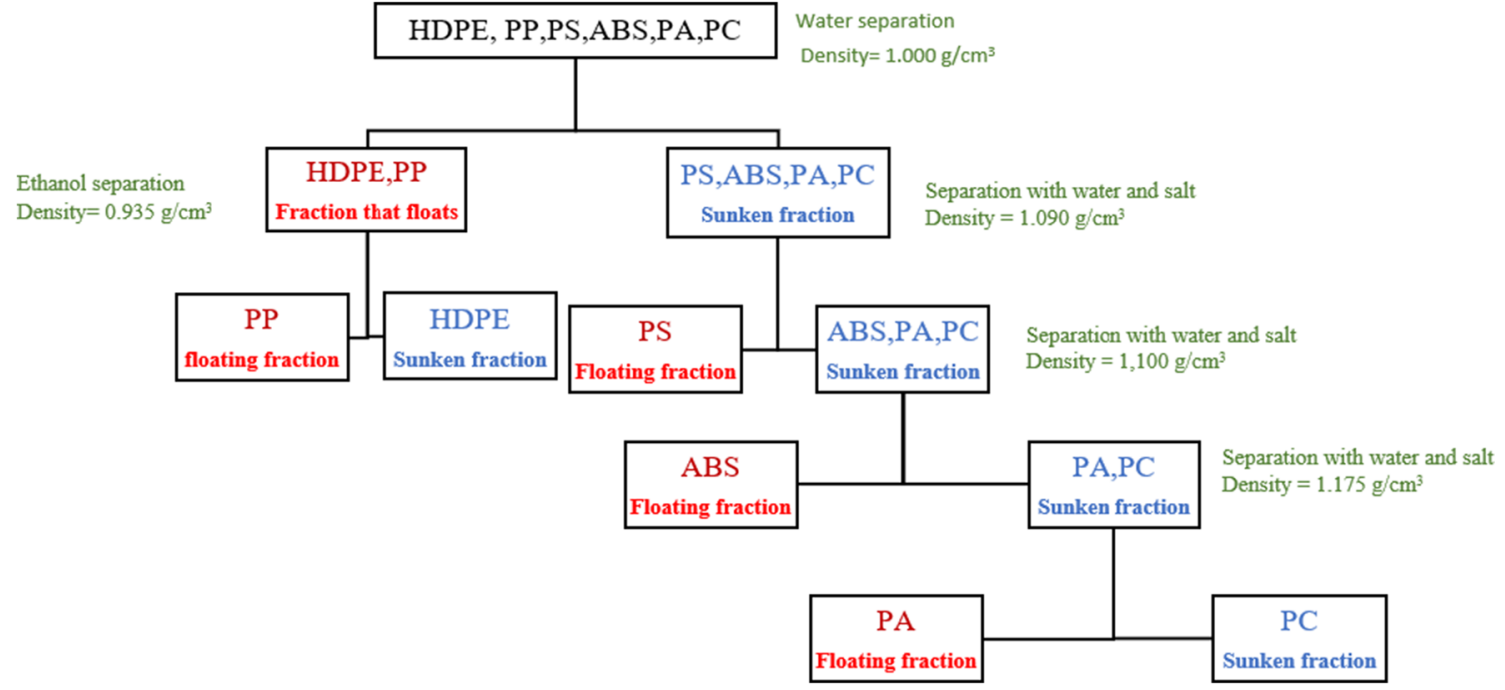

Fig. 1 Separation of virgin polymers (HDPE, PP, PS, ABS, PA and PC) in water and NaCl. The polymers written in red are those that float in the solution and the polymers written in blue sink in the solution used

fraction, mold, and metal plate was placed in its entirety in the hydraulic press for $10 \mathrm{~min}$ at $100 \mathrm{kN}$ pressure with a progressive $\mathrm{T}_{\mathrm{e}}$, increase in temperature until reaching melting temperature of a fraction. As a reference temperature $\left(T_{m}\right)$ to melt the separated fractions, the melting temperature of the virgin polymers was used. The temperature used to melt the fractions was between 20 and $-20 \%$ the melting temperature of the virgin polymer $\left(T_{f}\right)$, because the fractions were not considered pure polymers since they were mixed with fillers, inorganic additives and mixtures of impurities and irregularities. Subsequently, the temperature was lowered to $60^{\circ} \mathrm{C}$ to cool the molten plate. Identifying the type of plastic is contingent on the percentage of the plate's molten area.

$T_{f}$ melting temperature of virgin polymers, $T_{e}$ temperature range of the test

\section{Results}

\section{Separation of the virgin polymer mixture with $\mathrm{NaCl}$}

In order to separate HDPE, PP, PS, ABS, and PA polymers and $\mathrm{PC}$ mixture into individual polymers, an aqueous sodium chloride solution with various concentrations was used (Fig. 5). When only tap water used, 97.5 was recovered \% HDPE+PP. However, for an $11-12 \% \mathrm{w} / \mathrm{v} \mathrm{NaCl}$ concentration, most PS $(80.3 \%)$ floated to the surface, while ABS, PA, and PC sank to the bottom. With a further increase in solution concentration $(20 \% \mathrm{w} / \mathrm{v})$, the complete separation of ABS mixture $(84.8 \%)$ from the $\mathrm{PA}$ and $\mathrm{PC}$ polymers was achieved. For a $40 \% \mathrm{NaCl} \mathrm{w} / \mathrm{v}$ concentration, most of

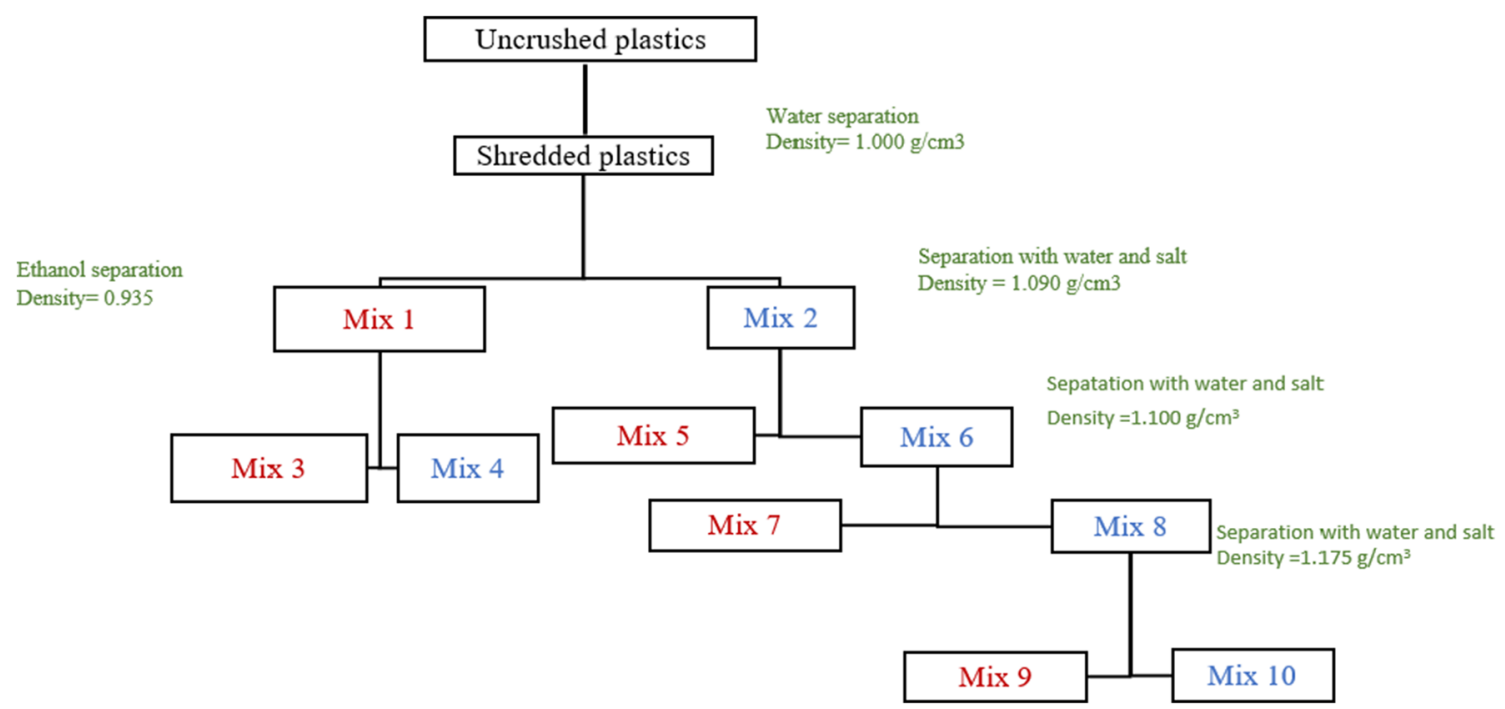

Fig. 2 Separation of post-consumer recyclable plastics using tap water, sodium chloride, and ethanol. The mixtures written with red color are those that float in the solution, while the mixtures written with blue color sink in the solution used 
Fig. 3 Post-consumer plastics from solid urban waste (MSW) before and after being shredded

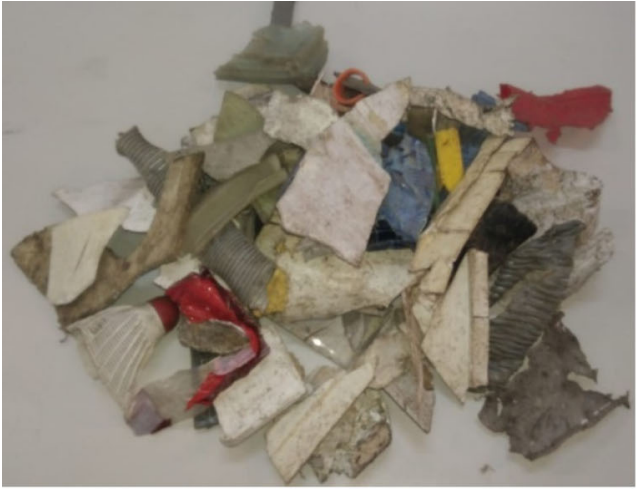

Plastics before shredding

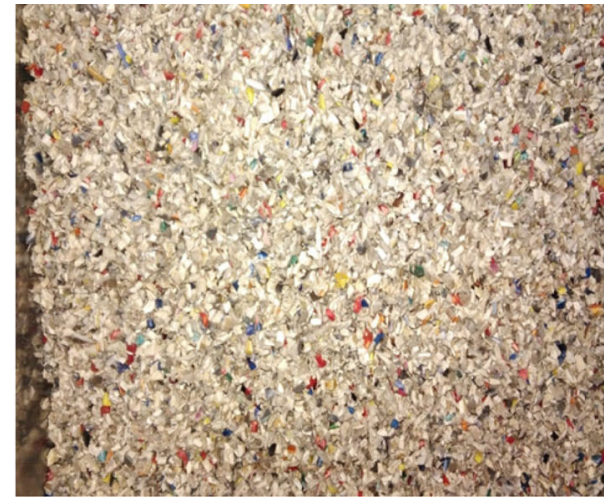

Shredded plastics the PA $(70 \%)$ floated to the surface of the solution, while $95.4 \%$ of the PC completely sunk.

\section{Separation of the virgin polymer mixture with $\mathrm{C}_{2} \mathrm{H}_{5} \mathrm{OH}$}

HDPE+PP fraction is previously separated with water and ethyl alcohol into individual polymers of PP and HDPE (Fig. 6). The PP, which floated, began to separate from the HDPE when a concentration of $23 \% \mathrm{v} / \mathrm{v}$ of $\mathrm{C}_{2} \mathrm{H}_{5} \mathrm{OH}$ was used, obtaining a recovery of $95.60 \%$. Complete separation of HDPE from PP was achieved when a concentration of $31 \%$ $\mathrm{v} / \mathrm{v}$ was used. However, the recovery fraction of HDPE was much higher $(99.70 \%)$. The experimental results demonstrated that the recoveries of HPDE and PP occurred for a density of the aqueous medium of 0.935 to $0.955 \mathrm{~g} / \mathrm{cm}^{3}$.

\section{Separation of the post-consumer plastic waste mix with $\mathrm{NaCl}$ and $\mathrm{C}_{2} \mathrm{H}_{5} \mathrm{OH}$}

In Fig. 7, six separate MSW plastic fractions are represented. Results showed that plastic waste was mainly composed from mixture $5(37.5 \%)$ and mixtures 3 and 4 with 15.4 and $14.1 \%$, respectively. According to the estimated densities of each separation mixture, the above mixtures could be related to the polymers of PS, PP, and HDPE. To a lesser extent the

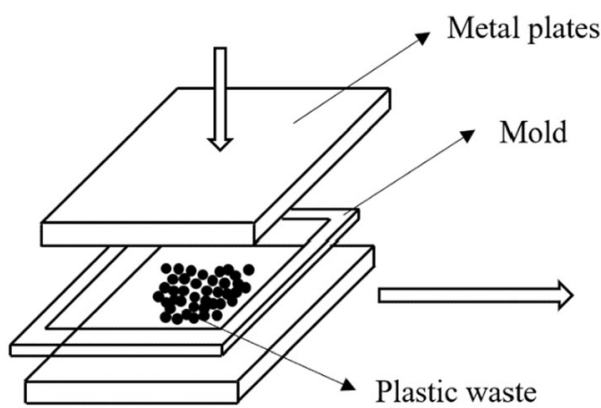

Compression scheme

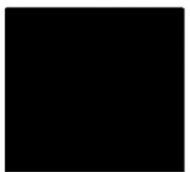

Plastic plate
Fig. 4 Process of obtaining the plates by means of the compression test mixtures 7; 9 and 10 represented $11.9 ; 8.5$ and $12.4 \%$, respectively that could be related to $\mathrm{ABS}, \mathrm{PA}$, and $\mathrm{PC}$ polymers with some PET and PVC. However, the different fractions are mixed with inorganic fillers and additives, causing properties to vary making the separated samples impure and inconsistent.

\section{Determining recycled polymers plates}

One of the objectives of making the plates is to observe color diversity present in them and determine if the material used melts completely at the polymer melting temperature. If the material melts completely, it means the material has been separated efficiently, that is, the material that makes up this fraction is sufficiently pure without the presence of other polymers, nor impurities and improprieties such as dirt, wood, glass, and metals. On the contrary, if the plate has discontinuous castings or burned areas, it means that the material has not completely melted, causing plate's heterogeneity due to polymer low purity.

Figure 8 shows the plates of post-consumer plastics obtained at different melting temperatures. Thus, for example, mixture 3 was melted at $175^{\circ} \mathrm{C}$, obtaining a high percentage of melting. The fraction did not present cracks and burned areas. However, the separated fraction had brown spots or spots. Stains caused by possible remains of wood and impurities that have prevented its complete melting. Based on the melting temperature and the density of the fraction, this mixture corresponds to HDPE (Fig. 8a). Similarly, mixture 4 melted at $195{ }^{\circ} \mathrm{C}$. The fraction presented few burned areas, denoting a more homogeneous cast, which indicated that according to its melting temperature and density it could be a fraction of PP (Fig. 8b). However, spots of different colors are still noticeable, indicating the presence of other polymers of similar density.

In Fig. 8c, a plate is represented that could mostly contain ABS due to its greater uniformity in its casting; the plate also shows some specific points where it is burned due to the presence of lower density polymers. On the other hand, the plate in Fig. 8d contains less impurity mixture due to the little 
Fig. 5 Separation of the PP+ $\mathrm{HDPE} / \mathrm{PS} / \mathrm{ABS} / \mathrm{PA} / \mathrm{PC}$ mixture by the sinking-flotation method with sodium chloride: recovery of the polymers and density of the aqueous sodium chloride solution

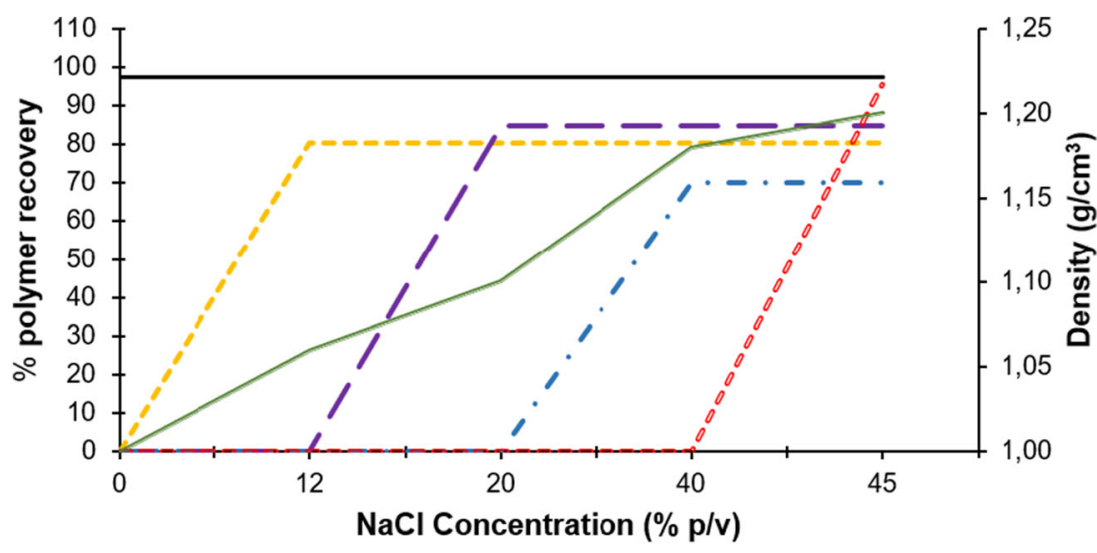

- - PS - - ABS - - PA 0000 PC —PP+HDPE —Density presence of cracks. However, it has areas that have not completely melted, meaning that there are higher density polymers. It also has some burned parts, indicating the presence of polyolefins and ABS.

Finally, the last two plates of fractions 9 and 10 could correspond to PA, PC, PET, and PVC due to their high densities. The plate in Fig. 8e shows many burned areas and cracks, implying that the purity of the mixture is not optimum because there is a mixture of different polymers. Moreover, the last plate (Fig. 8f) shows brown colors and many black spots because of impurities and improper elements presence (wood, glass soil, remains, and so on.). In addition, this plate has burned areas indicating that it has a lower melting point polymer blend.

\section{Discussion}

\section{Separation of the virgin polymer mixture with $\mathrm{NaCl}$}

Results showed that polyolefins and PC polymers are easier to recover by means of the float-sink technique due to their high

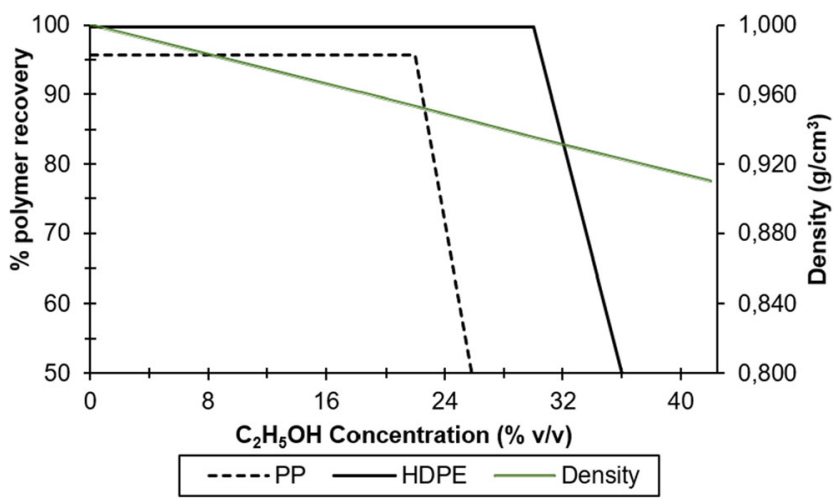

Fig. 6 Separation of HDPE from PP by means of a sinking-flotation process with an ethyl alcohol solution: recovery of the polymers and density of the aqueous sodium chloride solution. recovery percentage. The use of this technique is an interesting alternative to enhance the recycling process. Likewise, ABS and PS groups revealed high recovery percentages, while PA sample separation was not appealing since recovery percentages were quite low. The role played by medium density in the sinking-floating separation technique is a key parameter to separate plastic particles (Fu et al. 2017). For example, PE and PP, as lightweight plastics, can be easily separated by density sorting in the medium of water, while PVC and PET, as heavy plastics, are considered unmanageable plastic blends due to their similar density (Wang et al. 2020). In this study, separation with tap water made the polyolefins separate easily, since these polymers have specific densities lighter than those of water (Ito et al. 2010). The recovery data for polyolefins was higher than $97 \%$, results very similar to other studies in the literature. Thus, Gundupalli et al. (2017) through laser-induced degradation spectroscopy obtained $80-97 \%$ polyolefins recovery. Meanwhile, Wang et al. (2015) through foam flotation recovered PE and PP percentages higher than 97\%. Similarly, Serranti et al. (2015) through the magnetic density separation technique managed to recover more than $94 \%$ of polyolefins. Bonifazi et al. (2013) using hyperspectral imaging technology (HSI) obtained PE and PP recoveries higher than 96\%.

Other fractions that had high separation percentages were PS and ABS polymers. Obviously, these polymers possess an inherent buoyancy in higher density aqueous medium, making them manageable for recycling (Wang et al. 2016). Hence, there have been recoveries of over $80 \%$. The high recovery of PS and ABS suggests the presence of an inherent hydrophobic surface of the tested polymers (Du et al. 2020). PA $(70 \%)$ was the polymer that recovered the least. Their separation could be improved if a selective wetting of polymers was carried out, which allowed a reduction in surface tension (Wang et al. 2015; Alter 2005; Fraunholcz 2004). It should be considered that in this study a natural flotation of the polymers was carried out. One way to increase the recovery of PA 
Fig. 7 Range of densities and percentage composition of plastic types reported in post-consumer plastic waste from solid urban waste (MSW).

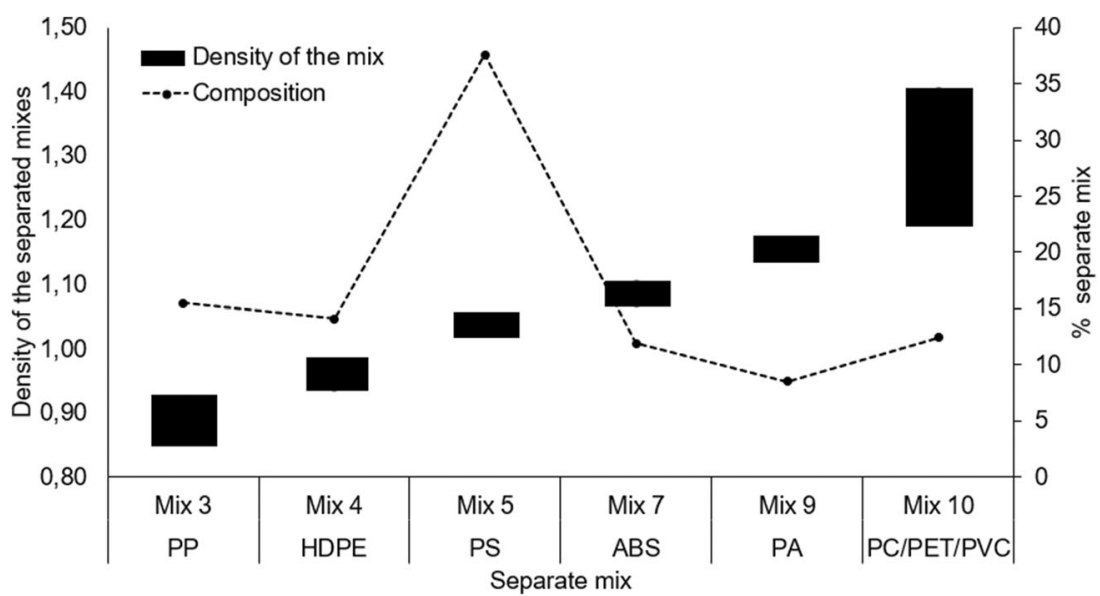

is to homogenize the size and shape of the particles. It has been proven in the literature that bar, elongated or irregular particles have greater buoyancy than angular and round particles in the same size range. Furthermore, fine particles float faster than coarse particles (Shen et al. 2001). However, the separation results were very consistent and much better than other previous studies. Qu et al. (2020), for example, through a natural flotation of ABS and PC, they achieved separation percentages of 68.41 and $59.4 \%$, respectively. Similarly, Pita and Castilho (2016) through the gravity jigging method, separated PS from PET and PVC and obtained separation efficiency ranges of $71-85 \%$. For their part, Tsunekawa et al. (2005) through the "Jig" gravity method separated plastics from discarded photocopying machines and managed to recover grades of $99.8 \% \mathrm{PS}, 99.3 \% \mathrm{ABS}$, and $98.6 \%$ PET.

\section{Separation of the virgin polymer mixture with $\mathrm{C}_{2} \mathrm{H}_{5} \mathrm{OH}$}

As it is widely known, both HDPE and PP polymers are naturally hydrophobic. Thus, the set of HDPE+PP samples is easy to separate from the rest of polymers with higher density. However, separating HDPE from PP requires a suitable solution due to their similarity in densities. Therefore, a suitable agent is necessary to achieve an individual selective polymer separation (Kangal and Üçerler 2018). In this study, ethanol as an aqueous solution modifying the separation medium was adequate allowing the two polymers to be separated with a high recovery percentage. However, slight differences in density between HDPE and PP, when separated with ethanol, caused slow sedimentation rates (Ferrara and Meloy 1999).

Additionally, the separation of the mixture between HDPE and PP began with a concentration below $23 \% \mathrm{v} / \mathrm{v}$ of $\mathrm{C}_{2} \mathrm{H}_{5} \mathrm{OH}$. Ethanol concentration was much lower than Pongstabodee et al. (2008), who used between 30 and 50\% $\mathrm{v} / \mathrm{v}$ of $\mathrm{C}_{2} \mathrm{H}_{5} \mathrm{OH}$ to separate HDPE from PP. Nevertheless, in this study, $4.11 \%$ additional PP was recovered than HDPE because PP polymer density was much closer than the aqueous medium. Generally, the use of the sink-float separation technique can be very effective in separating polyolefins from each other (Bauer et al. 2018), especially since recoveries close to $100 \%$ can be obtained.

\section{Post-consumer plastic waste separation using $\mathrm{NaCl}$ and $\mathrm{C}_{2} \mathrm{H}_{5} \mathrm{OH}$ mix}

In this study plastics were separated into 6 groups based on their estimated density. The obtained fractions demonstrated that the analyzed MSW plastic waste is mainly composed of ABS (mixture 7) and PS (mixture 5). These results are compatible with data from other studies showing that PS and ABS polymers are the most predominant polymers in vehicle waste (Zhang et al. 2020). According to Dahlbo et al. (2018) and Burange et al. (2015), MSW plastic waste is usually composed of PP and HDPE and to a lesser extent by PS (Karmakar 2020). However, variations in the percentage values of MSW plastic waste are usually associated with the consumption habits of the population (Vazquez et al. 2020).

In this research, mixture 10 comprised a $1.20-1.40 \mathrm{~g} / \mathrm{cm}^{3}$ density implying that the mixture was composed by more than one polymer of the same or similar density. In accordance with estimated density and the percentage of separation obtained, this mixture can be composed by PVC, PET, and some PC remains. In this case, the mixture represented between 8 and $12 \%$ of the total composition; values comparable to the estimates of Buekens and Yang (2014), who consider that PET, PVC could represent $10-15 \%$ of the waste from a car. On the other hand, PVC and PET plastic waste have similar density levels preventing them from being separated by sinking-floating. PET density changes from 1.33 to $1.37 \mathrm{~g} / \mathrm{cm}^{3}$ and PVC density is between 1.32 and $1.37 \mathrm{~g} / \mathrm{cm}^{3}$ (Burat et al. 2009). In other words, the separation of plastics of equal density is not possible by gravity methods (Hopewell et al. 2009). Hence, in mixture 10 a mixture of PET and PVC has been grouped together and they have not been separated into two different fractions. Furthermore, previous studies have 


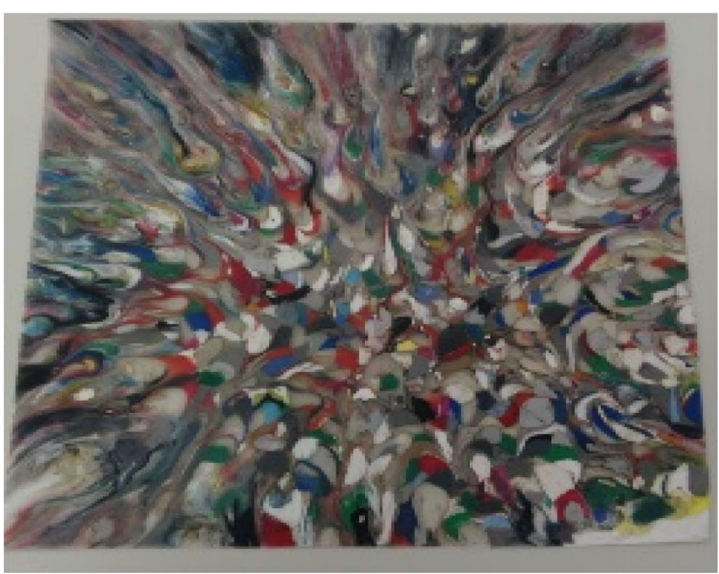

A) Mixture 3 (HDPE)

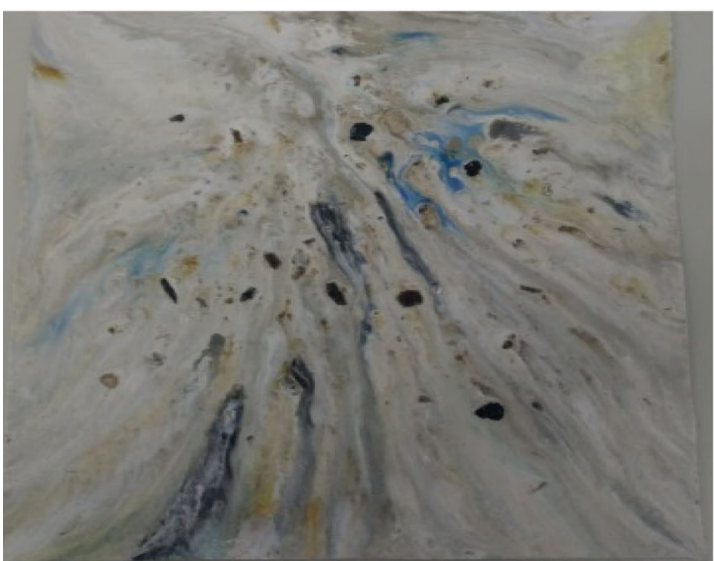

C) Mixture $7(\mathrm{ABS})$

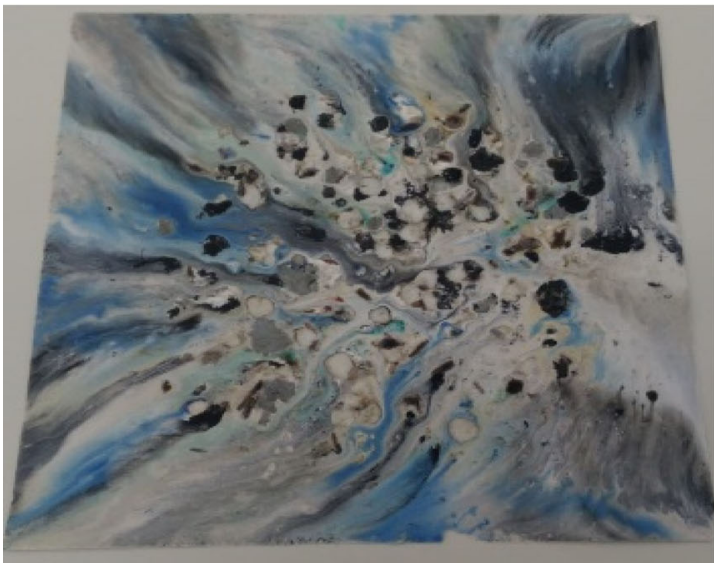

E) Mixture $9(\mathrm{PC})$

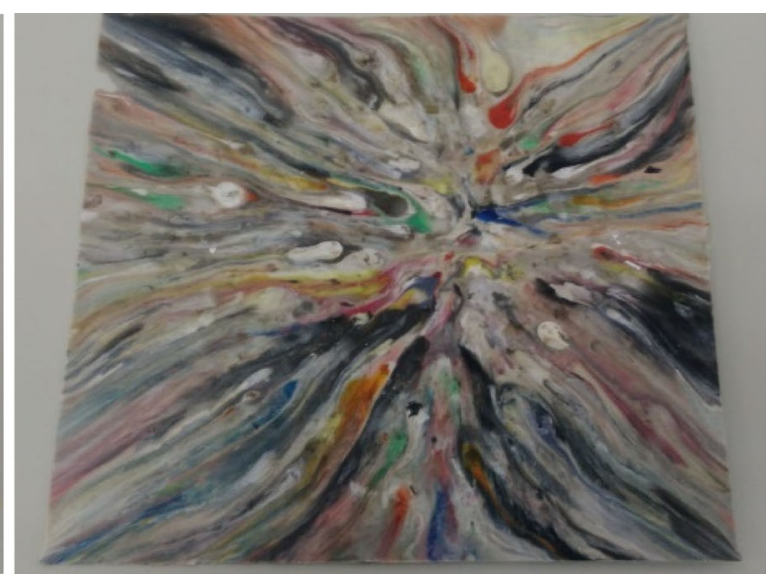

B) Mixture $4(\mathrm{PP})$

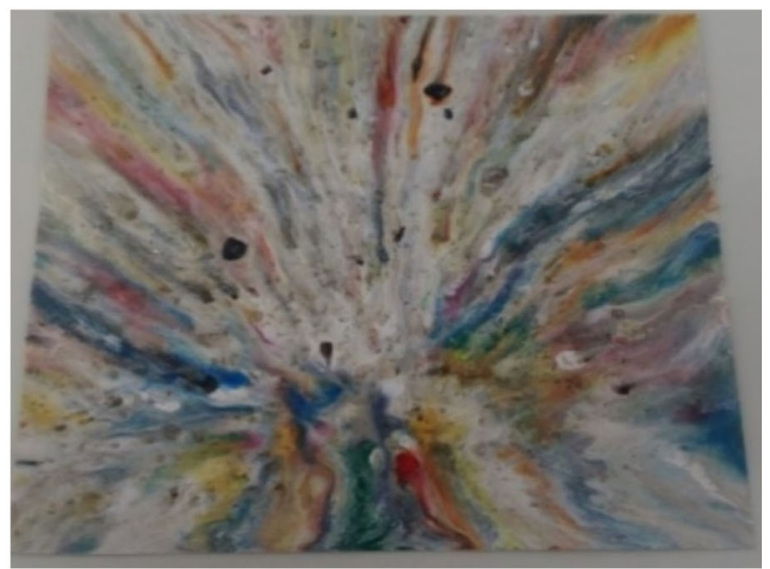

D) Mixture $5(\mathrm{PS})$

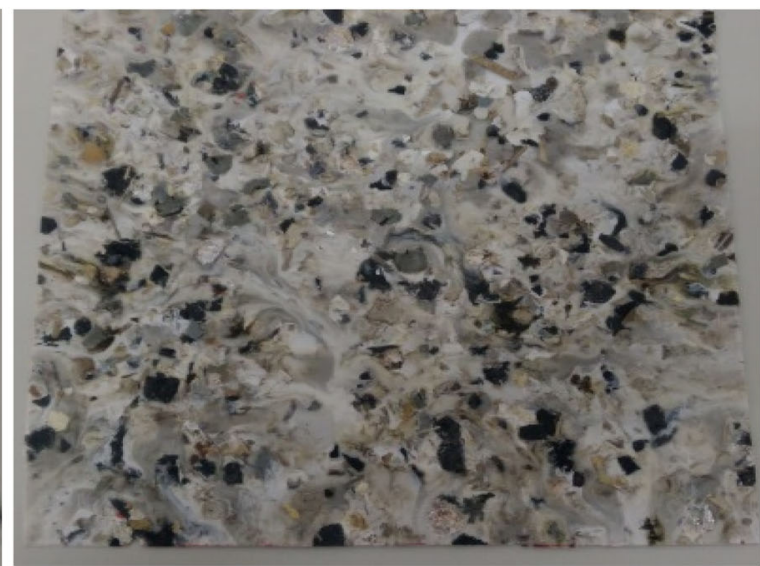

F) Mixture 10 (PET,PVC)

Fig. 8 Plates of post-consumer plastic waste melted at different melting temperatures. Mixture 3 was melted at $175^{\circ} \mathrm{C}$, Mixture 4 at $195{ }^{\circ} \mathrm{C}$, Mixture 5 at $220^{\circ} \mathrm{C}$, Mixture 7 at $235^{\circ} \mathrm{C}$, Mixture 9 at $240{ }^{\circ} \mathrm{C}$, and Mixture 10 at $185^{\circ} \mathrm{C}$

found that a strong alkaline solution of $\mathrm{NaOH}$ could destroy the hydrophobicity of one of the polymers (Burat et al. 2009; Kangal 2010), preventing the separation by sinking-floating. However, to improve its reproducibility, it is advisable to combine the sink-float technique with other separation techniques to increase the separation efficiency. To optimize the technique, it is advisable to carry it out in stages, that is, to subject the previously separated fractions to a new densification with the same dense medium. 


\section{Determination of plates of recycled polymers}

In general, plates contain more than $90 \%$ cast, as a result they melted above virgin polymers melting temperature because of the presence of inorganic additives, fillers and possible foaming agents as it was reflected by burned and cracked areas generated during combustion. The fact that the plates have undergone this type of reactions is due to the fact that the foaming material is usually composed by a large number of small foam holes often known as porous polymeric material (Jin et al. 2019). In addition, polymer foam is widely used and plays an important role in the automotive industry (Zhang et al. 2018; Li et al. 2018a, b; Wang et al. 2017; Wang et al. 2018; Li et al. 2018a, b). The results also revealed that the plates presented a variable homogeneity of the polymers, which indicated the presence of more than one polymer in each mixture. This is because the foamers cause the density of the mixture to decrease, causing the plastic material to vary its density.

\section{Conclusion}

This study includes virgin polymers separation by sinkingflotation (HDPE, PP, PS, ABS, PA and PC) and mixed plastic waste from municipal solid waste. The sink-float method with water was highly effective in separating HDPE and PP polymers as up to $97.5 \%$ was recovered. Separation of individual HDPE and PP fractions occurred as concentrations of $23 \% \mathrm{v} / \mathrm{v}$ of ethanol were used, obtaining 96\% HDPE and 99.7\% PP recoveries. Likewise, higher density polymers (PA, PS, ABS, and $\mathrm{PC}$ ) separation results turned out promising, since recoveries of 70-85\% approximately were obtained. Sodium chloride concentration used to separate the polymers was 11-40\% w/v. Finally, as per MSW plastics, $29.6 \%$ of separate fractions were obtained for polyolefins, $37.54 \%$ for PS, $11 \%$ for ABS, $8 \%$ for PA, and $12 \%$ for PC, PET, and PVC.

\begin{abstract}
Acknowledgements This work has been carried out within the framework of the project "Analysis of the implementation of biomass exploitation chains in rural communities in the province of Bolívar (Ecuador)" of the ADSIEO-COOPERATION program of the Polytechnic University of Valencia (UPV). The Ecuadorian Energy Exploitation Research Network of Biomass (ECUMASA) and the IBEROMASA Network of the Ibero-American Program of Science and Technology for Development (CYTED) have participated in this program.
\end{abstract}

Authors' contributions Contribution of each co-author is described below:

OWMQ performed the conceptualization, methodology, validation, formal analysis, investigation, and writing-original draft preparation.

BVM performed the conceptualization, methodology, validation, formal analysis, investigation, writing - original draft preparation, writing review and editing and funding acquisition. He also performed the methodology, validation, writing review and editing and funding acquisition.
AFG performed the formal analysis, funding acquisition, and the writing review and editing.

Funding Open Access funding provided thanks to the CRUE-CSIC agreement with Springer Nature.

Availability of data and materials The datasets during the current study are available from the corresponding author on reasonable request.

\section{Declarations}

Ethics approval and consent to participate Not applicable.

Consent for publication Not applicable.

Competing interests The authors declare that they have no competing interests.

Open Access This article is licensed under a Creative Commons Attribution 4.0 International License, which permits use, sharing, adaptation, distribution and reproduction in any medium or format, as long as you give appropriate credit to the original author(s) and the source, provide a link to the Creative Commons licence, and indicate if changes were made. The images or other third party material in this article are included in the article's Creative Commons licence, unless indicated otherwise in a credit line to the material. If material is not included in the article's Creative Commons licence and your intended use is not permitted by statutory regulation or exceeds the permitted use, you will need to obtain permission directly from the copyright holder. To view a copy of this licence, visit http://creativecommons.org/licenses/by/4.0/.

\section{References}

Achilias DS, Roupakias C, Megalokonomos P, Lappas AA, Antonakou EV (2007) Chemical recycling of plastic wastes made from polyethylene (LDPE and HDPE) and polypropylene (PP). J Hazard Mater 149:536-542. https://doi.org/10.1016/j.jhazmat.2007.06.076

Aljerf L (2016) Green technique development for promoting the efficiency of pulp slurry reprocess. Sci J King Faisal Univ 17:1-10. https:// doi.org/10.1007/978-3-319-18744-0

Al-Salem SM (2019) Influential parameters on natural weathering under harsh climatic conditions of mechanically recycled plastic film specimens. J Environ Manag 230:355-365. https://doi.org/10.1016/j. jenvman.2018.09.044

Alter H (2005) The recovery of plastics from waste with reference to froth flotation. Resour Conserv Recycl 43:119-132. https://doi.org/10. 1016/j.resconrec.2004.05.003

Ayeleru OO, Dlova S, Akinribide OJ, Ntuli F, Kupolati WK, Marina PF, Blencowe A, Olubambi PA (2020) Challenges of plastic waste generation and management in sub-Saharan Africa: A review. Waste Manag 110:24-42. https://doi.org/10.1016/j.wasman.2020.04.017

Bauer M, Lehner M, Schwabl D, Flachberger H, Kranzinger L, Pomberger R, Hofer W (2018) Sink-float density separation of post-consumer plastics for feedstock recycling. J Mater Cycles Waste Manag 20: 1781-1791. https://doi.org/10.1007/s10163-018-0748-z

Bing X, Bloemhof JM, Ramos TRP, Barbosa-Povoa AP, Wong CY, van der Vorst JGAJ (2016) Research challenges in municipal solid waste logistics management. Waste Manag 48:584-592. https://doi.org/ 10.1016/j.wasman.2015.11.025 
Bonifazi G, D’Agostini M, Dall'Ava A, Serranti S, Turioni F (2013) A new hyperspectral imaging based device for quality control in plastic recycling. In: Proc.SPIE. https://doi.org/10.1117/12.2014909

Bucknall DG (2020) Plastics as a materials system in a circular economy. Philos Trans R Soc A Math Phys Eng Sci 378:20190268. https://doi. org/10.1098/rsta.2019.0268

Buekens A, Yang J (2014) Recycling of WEEE plastics: a review. J Mater Cycles Waste Manag 16:415-434. https://doi.org/10.1007/ s10163-014-0241-2

Burange AS, Gawande MB, Lam FLY, Jayaram RV, Luque R (2015) Heterogeneously catalyzed strategies for the deconstruction of high density polyethylene: plastic waste valorisation to fuels. Green Chem 17:146-156. https://doi.org/10.1039/C4GC01760A

Burat F, Güney A, Olgaç Kangal M (2009) Selective separation of virgin and post-consumer polymers (PET and PVC) by flotation method. Waste Manag 29:1807-1813. https://doi.org/10.1016/j.wasman. 2008.12.018

Chand Malav L, Yadav KK, Gupta N, Kumar S, Sharma GK, Krishnan S, Rezania S, Kamyab H, Pham QB, Yadav S, Bhattacharyya S, Yadav VK, Bach QV (2020) A review on municipal solid waste as a renewable source for waste-to-energy project in India: Current practices, challenges, and future opportunities. J Clean Prod 277: 123227. https://doi.org/10.1016/j.jclepro.2020.123227

Chen X, Xi F, Geng Y, Fujita T (2011) The potential environmental gains from recycling waste plastics: Simulation of transferring recycling and recovery technologies to Shenyang, China. Waste Manag 31: 168-179. https://doi.org/10.1016/j.wasman.2010.08.010

Dahlbo H, Poliakova V, Mylläri V, Sahimaa O, Anderson R (2018) Recycling potential of post-consumer plastic packaging waste in Finland. Waste Manag 71:52-61. https://doi.org/10.1016/j. wasman.2017.10.033

Dodbiba G, Haruki N, Shibayama A, Miyazaki T, Fujita T (2002) Combination of sink-float separation and flotation technique for purification of shredded PET-bottle from PE or PP flakes. Int J Miner Process 65:11-29. https://doi.org/10.1016/S0301-7516(01) 00056-4

Du Y, Zhang Y, Jiang H, Li T, Luo M, Wang L, Wang C, Wang H (2020) Hydrophilic modification of polycarbonate surface with surface alkoxylation pretreatment for efficient separation of polycarbonate and polystyrene by froth flotation. Waste Manag 118:471-480. https://doi.org/10.1016/j.wasman.2020.09.006

Ferrara G, Meloy TP (1999) Low dense media process: a new process for low-density solid separation. Powder Technol 103:151-155. https:// doi.org/10.1016/S0032-5910(98)00216-2

Ferronato N, Torretta V (2019) Waste Mismanagement in Developing Countries: A Review of Global Issues. Int J Environ Res Public Health 16:1060. https://doi.org/10.3390/ijerph16061060

Fraunholcz N (2004) Separation of waste plastics by froth flotation - a review, part I. Miner Eng 17:261-268. https://doi.org/10.1016/j. mineng.2003.10.028

Fu S, Fang Y, Yuan H, Tan W, Dong Y (2017) Effect of the medium's density on the hydrocyclonic separation of waste plastics with different densities. Waste Manag 67:27-31. https://doi.org/10.1016/j. wasman.2017.05.019

Geyer R, Jambeck JR, Law KL (2017) Production, use, and fate of all plastics ever made. Sci Adv 3:e1700782. https://oi.org/10.1126/ sciadv. 1700782

$\mathrm{Gu}$ L, Ozbakkaloglu T (2016) Use of recycled plastics in concrete: A critical review. Waste Manag 51:19-42. https://doi.org/10.1016/j. wasman.2016.03.005

Gundupalli SP, Hait S, Thakur A (2017) A review on automated sorting of source-separated municipal solid waste for recycling. Waste Manag 60:56-74. https://doi.org/10.1016/j.wasman.2016.09.015

Guney A, Poyraz MI, Kangal O, Burat F (2013) Investigation of thermal treatment on selective separation of post consumer plastics prior to froth flotation. Waste Manag 33:1795-1799. https://doi.org/10. 1016/j.wasman.2013.05.006

Gupta N, Yadav KK, Kumar V (2015) A review on current status of municipal solid waste management in India. J Environ Sci 37: 206-217. https://doi.org/10.1016/j.jes.2015.01.034

Hopewell J, Dvorak R, Kosior E (2009) Plastics recycling: challenges and opportunities. Philos Trans R Soc Lond Ser B Biol Sci 364:21152126. https://doi.org/10.1098/rstb.2008.0311

Hu B, Serranti S, Fraunholcz N, Di Maio F, Bonifazi G (2013) Recyclingoriented characterization of polyolefin packaging waste. Waste Manag 33:574-584. https://doi.org/10.1016/j.wasman.2012.11.018

Huang D-Y, Zhou S-G, Hong W, Feng W-F, Tao L (2013) Pollution characteristics of volatile organic compounds, polycyclic aromatic hydrocarbons and phthalate esters emitted from plastic wastes recycling granulation plants in Xingtan Town, South China. Atmos Environ 71:327-334. https://doi.org/10.1016/j.atmosenv. 2013.02.011

Huysman S, De Schaepmeester J, Ragaert K, Dewulf J, De Meester S (2017) Performance indicators for a circular economy: A case study on post-industrial plastic waste. Resour Conserv Recycl 120:46-54. https://doi.org/10.1016/j.resconrec.2017.01.013

Ito M, Tsunekawa M, Ishida E, Kawai K, Takahashi T, Abe N, Hiroyoshi N (2010) Reverse jig separation of shredded floating plastics separation of polypropylene and high density polyethylene. Int $\mathrm{J}$ Miner Process 97:96-99. https://doi.org/10.1016/j.minpro.2010.08. 007

Jin F-L, Zhao M, Park M, Park S-J (2019) Recent Trends of Foaming in Polymer Processing: A Review. Polymers (Basel) 11:953. https:// doi.org/10.3390/polym11060953

Kangal MO (2010) Selective Flotation Technique for Separation of PET and HDPE Used in Drinking Water Bottles. Miner Process Extr Metall Rev 31:214-223. https://doi.org/10.1080/08827508.2010. 483362

Kangal MO, Üçerler Z (2018) Recycling of Virgin and Post-Consumer Polypropylene and High Density Polyethylene. Int Polym Process 33:268-275. https://doi.org/10.3139/217.3506

Karmakar GP (2020) Regeneration and Recovery of Plastics. Ref Modul Mater Sci Mater Eng. https://doi.org/10.1016/B978-0-12-820352-1. 00045-6

Lackner M (2015) Bioplastics-Biobased plastics as renewable and/or biodegradable alternatives to petroplastics. Kirk-Othmer Encycl Chem Technol:1-41. https://doi.org/10.1002/0471238961.koe00006

Law KL, Starr N, Siegler TR, Jambeck JR, Mallos NJ, Leonard GH (2020) The United States' contribution of plastic waste to land and ocean. Sci Adv 6:288. https://doi.org/10.1126/sciadv.abd0288

Li M, Qiu J, Xing H, Fan D, Wang S, Li S, Jiang Z, Tang T (2018a) Insitu cooling of adsorbed water to control cellular structure of polypropylene composite foam during $\mathrm{CO} 2$ batch foaming process. Polymer (Guildf) 155:116-128. https://doi.org/10.1016/j.polymer. 2018.09.034

Li R, Lin H, Lan P, Gao J, Huang Y, Wen Y, Yang W (2018b) Lightweight cellulose/carbon fiber composite foam for electromagnetic interference (EMI) shielding. Polymers (Basel) 10:1319. https://doi.org/10.3390/polym10121319

Mancheno M, Astudillo S, Arévalo P, Malo I, Naranjo T, Espinoza J (2016) Aprovechamiento energético de residuos plásticos obteniendo combustibles líquidos, por medio de pirólisis. La Granja 23:1. https://doi.org/10.17163/lgr.n23.2016.06

Mumbach GD, de Sousa CR, Machado RAF, Bolzan A (2019) Dissolution of adhesive resins present in plastic waste to recover polyolefin by sink-float separation processes. J Environ Manag 243:453-462. https://doi.org/10.1016/j.jenvman.2019.05.021

Pita F, Castilho A (2016) Influence of shape and size of the particles on jigging separation of plastics mixture. Waste Manag 48:89-94. https://doi.org/10.1016/j.wasman.2015.10.034 
Pita F, Castilho A (2017) Separation of plastics by froth flotation. The role of size, shape and density of the particles. Waste Manag 60:9199. https://doi.org/10.1016/j.wasman.2016.07.041

Pol VG, Thiyagarajan P (2010) Remediating plastic waste into carbon nanotubes. J Environ Monit 12:455-459. https://doi.org/10.1039/ B914648B

Pongstabodee S, Kunachitpimol N, Damronglerd S (2008) Combination of three-stage sink-float method and selective flotation technique for separation of mixed post-consumer plastic waste. Waste Manag 28:475-483. https://doi.org/10.1016/j.wasman.2007.03.005

Qu Y h, Li Y p, Zou X t, Xu K w, Xue Y t (2020) Microwave treatment combined with wetting agent for an efficient flotation separation of acrylonitrile butadiene styrene (ABS) from plastic mixtures. J Mater Cycles Waste Manag 23:96-106. https://doi.org/10.1007/s10163020-01099-y

Rahimi A, García JM (2017) Chemical recycling of waste plastics for new materials production. Nat Rev Chem 1:46. https://doi.org/10. 1038/s41570-017-0046

Ruj B, Pandey V, Jash P, Srivastava V (2015) Sorting of plastic waste for effective recycling. Int J Appl Sci Eng Res 4. https://doi.org/10. 6088/ijaser.04058

Serranti S, Luciani V, Bonifazi G, Hu B, Rem PC (2015) An innovative recycling process to obtain pure polyethylene and polypropylene from household waste. Waste Manag 35:12-20. https://doi.org/10. 1016/j.wasman.2014.10.017

Sharma HB, Vanapalli KR, Cheela VRS, Ranjan VP, Jaglan AK, Dubey B, Goel S, Bhattacharya J (2020) Challenges, opportunities, and innovations for effective solid waste management during and post COVID-19 pandemic. Resour Conserv Recycl 162:105052. https:// doi.org/10.1016/j.resconrec.2020.105052

Shen H, Forssberg E, Pugh RJ (2001) Selective flotation separation of plastics by particle control. Resour Conserv Recycl 33:37-50. https://doi.org/10.1016/S0921-3449(01)00056-8

Shimoiizaka J, Kounosu A, Hayashi Y, Saito K (1976) A new type sinkfloat separator for waste plastics. J Min Metall Inst Japan 92:675679. https://doi.org/10.2473/shigentosozai1953.92.1064 675

Singh N, Hui D, Singh R, Ahuja IPS, Feo L, Fraternali F (2017) Recycling of plastic solid waste: A state of art review and future applications. Compos Part B Eng 115:409-422. https://doi.org/10. 1016/j.compositesb.2016.09.013

Takoungsakdakun T, Pongstabodee S (2007) Separation of mixed postconsumer PET-POM-PVC plastic waste using selective flotation. Sep Purif Technol 54:248-252. https://doi.org/10.1016/j.seppur. 2006.09.011

Tsunekawa M, Naoi B, Ogawa S, Hori K, Hiroyoshi N, Ito M, Hirajima T (2005) Jig separation of plastics from scrapped copy machines. Int J Miner Process 76:67-74. https://doi.org/10.1016/j.minpro.2004.12. 001
Tue NM, Goto A, Takahashi S, Itai T, Asante KA, Kunisue T, Tanabe S (2016) Release of chlorinated, brominated and mixed halogenated dioxin-related compounds to soils from open burning of e-waste in Agbogbloshie (Accra, Ghana). J Hazard Mater 302:151-157. https://doi.org/10.1016/j.jhazmat.2015.09.062

Vazquez YV, Barragán F, Castillo LA, Barbosa SE (2020) Analysis of the relationship between the amount and type of MSW and population socioeconomic level: Bahía Blanca case study, Argentina. Heliyon 6:e04343. https://doi.org/10.1016/j.heliyon.2020.e04343

Vitorino de Souza Melaré A, Montenegro González S, Faceli K, Casadei V (2017) Technologies and decision support systems to aid solidwaste management: a systematic review. Waste Manag 59:567-584. https://doi.org/10.1016/j.wasman.2016.10.045

Wang C, Wang H, Fu J, Liu Y (2015) Flotation separation of waste plastics for recycling - A review. Waste Manag 41:28-38. https:// doi.org/10.1016/j.wasman.2015.03.027

Wang C, Wang H, Gu G, Lin Q, Zhang L, Huang L, Zhao J (2016) Ammonia modification for flotation separation of polycarbonate and polystyrene waste plastics. Waste Manag 51:13-18. https:// doi.org/10.1016/j.wasman.2016.02.037

Wang G, Zhao J, Yu K, Mark LH, Wang G, Gong P, Park CB, Zhao G (2017) Role of elastic strain energy in cell nucleation of polymer foaming and its application for fabricating sub-microcellular TPU microfilms. Polymer (Guildf) 119:28-39. https://doi.org/10.1016/j. polymer.2017.05.016

Wang L, Wu Y-K, Ai F-F, Fan J, Xia Z-P, Liu Y (2018) Hierarchical Porous Polyamide 6 by Solution Foaming: Synthesis. Characterization and Properties Polymers (Basel) 10. https://doi. org/10.3390/polym10121310

Wang K, Zhang Y, Zhong Y, Luo M, Du Y, Wang L, Wang H (2020) Flotation separation of polyethylene terephthalate from waste packaging plastics through ethylene glycol pretreatment assisted by sonication. Waste Manag 105:309-316. https://doi.org/10.1016/j. wasman.2020.02.021

Zhang S, Lin Y, Ye L, Gu Y, Qiu J, Tang T, Li M (2018) Unexpected foaming behavior of heterografted comb-like PS-g-(PS/PE) copolymers with high branching density at semi-solid state under $\mathrm{CO} 2$ batching foam. Polymer (Guildf) 146:304-311. https://doi.org/10. 1016/j.polymer.2018.05.050

Zhang Y, Jiang H, Wang H, Wang C (2020) Separation of hazardous polyvinyl chloride from waste plastics by flotation assisted with surface modification of ammonium persulfate: Process and mechanism. J Hazard Mater 389:121918. https://doi.org/10.1016/j. jhazmat.2019.121918

Publisher's note Springer Nature remains neutral with regard to jurisdictional claims in published maps and institutional affiliations. 